\title{
Produção de biomassa de cana-de-açúcar em fase de estabelecimento
}

\section{Odair Honorato de Oliveira1, Mariana Cabral Pinto², Jonathan Bernardo Barboza ${ }^{3}$, Djalma Euzébio Simões Neto $^{4}$, João de Andrade Dutra Filho5, Lauter Silva Souto ${ }^{6}$, Rômulo Gil de Luna ${ }^{7}$ e Anielson dos Santos Souza ${ }^{7}$}

\begin{abstract}
${ }^{1}$ Universidade Federal do Grande Dourados. Curso de Pós-Graduação em Agronomia. Rodovia Dourados/Itahum, km 12. Unidade II. Dourados-MS, Brasil (CEP 79804-970).

${ }^{2}$ Engenheira Agrônoma, Avenida Campo Grande. Primavera do Leste-MT, Brasil (CEP 78850-000).

${ }^{3}$ Universidade Federal de Campina Grande. Centro de Ciência e Tecnologia Agroalimentar. Curso de Graduação em Agronomia. Rua Jairo Vieira Feitosa, 1770. Pombal-PB, Brasil (CEP 58840-000).

${ }^{4}$ Universidade Federal Rural de Pernambuco. Estação Experimental de Cana-deAçúcar do Carpina. Bairro Novo, Carpina-PE, Brasil (CEP 55812-010).

${ }^{5}$ Universidade Federal de Pernambuco. Centro Acadêmico Vitória. Rua dos Borges, S/№. Bela Vista. Vitória de Santo Antão-PE, Brasil (CEP 55608-250).

${ }^{6}$ Universidade Federal de Campina Grande, Centro de Ciência e Tecnologia Agroalimentar. Rua Jairo Vieira Feitosa, 1770. Pombal-PB, Brasil (CEP 58840-000). 7Universidade Federal de Campina Grande, Centro de Ciência e Tecnologia Agroalimentar. Rua Jairo Vieira Feitosa, 1770, Pombal-PB, Brasil (CEP 58840-000).
\end{abstract}

Resumo. Nos últimos anos a área cultivada e a produtividade de cana-de-açúcar cresceu substancialmente devido a novas variedades desenvolvidas em programas de melhoramento e de manejo varietal adequados. Obejtivou-se neste trabalho, avaliar a ação de doses de nitrogênio no crescimento inicial de duas novas variedades de cana-de-açúcar liberadas pela Rede Interuniversitária para o Desenvolvimento do Setor Sucroenergético. A pesquisa foi desenvolvida no Centro de Ciências e Tecnologia Agroalimentar da Universidade Federal de Campina Grande, Campus de Pombal. Utilizou-se o delineamento experimental de blocos ao acaso, em esquema fatorial, $2 \times 5$, correspondente a duas variedades (RB992506 e RB002754) de cana-de-açúcar em cinco doses de adubação nitrogenada com quatro repetições, totalizando 40 unidades experimentais. Foram avaliadas as seguintes características: número de folhas, área foliar, altura, diâmetro médio e número de colmos, massa fresca e seca das folhas e do total da parte aérea. Os dados foram submetidos à análise de variância e de regressão. As médias foram agrupadas pelo teste Scott-Knott a $5 \%$ de probabilidade e estimados os parâmetros genéticos. 0 coeficiente de

Recebido $31 / 07 / 2020$

Aceito

03/11/2020

Disponível on line $05 / 11 / 2020$

Publicado $31 / 12 / 2020$

Acesso aberto

ISSN 2359-1412/RBGAS-2020-0116/2020/7/17/22/1379 
determinação genotípico mostrou-se elevado para a maioria das características, indicando que a resposta das variedades à adubação nitrogenada deveu-se, em sua maior parte, a efeitos genéticos, com potencial de transmissão em trabalhos de hibridação. A aplicação de doses crescentes de nitrogênio propiciou aumentos significativos no desenvolvimento das variedades estudadas, tendo os melhores resultados alcançados pela variedade RB992506.

Palavras-chave: Manejo varietal; Melhoramento genético; Produção vegetal; Saccharum spp.

Abstract. Sugarcane biomass production in the establishment phase. Mass production and genetic parameters of two sugarcane cultivars submitted to five nitrogen doses in the establishment phase. In recent years, the cultivated area and the productivity of sugarcane have grown substantially, due to new varieties developed in breeding programs and adequate varietal management. The objective was to evaluate the action of nitrogen doses in the initial growth of two new varieties of sugarcane released by the Interuniversity Network for the Development of the Sugar-Energy Sector. The research was carried out at the Center for Science and Agri-Food Technology at the Federal University of Campina Grande, Pombal Campus. A randomized block design was used, in a 2 x 5 factorial scheme, corresponding to two varieties (RB992506 and RB002754) of sugar cane in five doses of nitrogen fertilization with four replications, totaling 40 experimental units. The following characteristics were evaluated: number of leaves, leaf area, stem height, average stem diameter, number of stems, fresh and dry mass of leaves, fresh and dry mass of stems, total fresh and dry mass of the aerial part. The data were submitted to analysis of variance and regression, the means were grouped by the Scott-Knott test at $5 \%$ probability and the genetic parameters were estimated. The genotypic determination coefficient was shown to be high for most traits, indicating that the response of varieties to nitrogen fertilization is mostly due to genetic effects with potential for transmission in hybridization works. The application of increasing doses of nitrogen led to significant increases in the growth of varieties and the best results were seen in the RB992506 variety.

Keywords: Varietal management; Genetic breeding; Vegetal production; Saccharum spp.

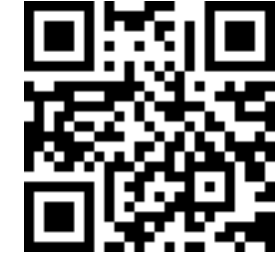

ORCID

(D) 0000-0001-5462-241X

Odair Honorato de Oliveira

(ㄱ) 0000-0001-7795-3174

Mariana Cabral Pinto

(D) 0000-0001-8194-326X

Jonathan Bernardo

Barboza

D 0000-0002-8313-0235

Djalma Euzébio

Simões Neto

(D) 0000-0002-9515-7267

João de Andrade Dutra

Filho

(D) 0000-0002-1053-0297

Lauter Silva Souto

(1) 0000-0002-8350-5615

Rômulo Gil de Luna

(1) 0000-0003-0145-0989

Anielson dos Santos

Souza

\section{Introdução}

No nordeste brasileiro, a produtividade de cana-de-açúcar é fortemente influenciada pela interação genótipo x ambiente, devido a irregularidade das chuvas, relevo e heterogeneidade de solos, os quais, em sua maioria, são de baixa fertilidade (Dutra Filho et al., 2015; Fabris et al., 2013). 
A adubação é um fator muito importante para o aumento da produtividade de cana-de-açúcar, sendo o nitrogênio o nutriente requerido em maior quantidade pela cultura nas fases iniciais do ciclo fenológico, porém sua disponibilidade é limitada na maioria dos solos que acaba por limitar a produtividade dos canaviais brasileiros (Pires et al., 2018). Por ser uma cultura que apresenta metabolismo C4, caracterizado por altas taxas de fotossínteses líquidas e eficiência na utilização do nitrogênio e da energia solar, à cana-de-açúcar apresenta demandas significativas de nitrogênio para o seu desenvolvimento (Fernandes et al., 2016).

O nitrogênio desempenha papel fundamental na produção de biomassa, podendo gerar efeitos sinérgicos na absorção de outros nutrientes como fósforo, potássio e magnésio, após a senescência das folhas velhas, além de participar da síntese de moléculas orgânicas como os aminoácidos e proteínas, sendo ainda ativador de enzimas para realização de processos vitais da planta (Okumura et al., 2011). Esses autores ainda apontam o nitrogênio como o elemento causador de maiores efeitos nas características da planta relacionadas ao crescimento e desenvolvimento, que afetam a produtividade da cultura.

A dose de nitrogênio a ser aplicada é uma decisão importante no manejo de fertilizantes, que deve levar em consideração vários fatores como: condições edafoclimáticas, sistema de cultivo, época de semeadura, rotação de culturas, época e modo de aplicação, aspectos econômicos e operacionais (Okumura et al., 2011). Todos esses fatores fazem com que a adubação nitrogenada necessite de ajustes na sua recomendação. Para Malavolta (1981), procurar conhecer as exigências nutricionais das plantas, principalmente no início de seu crescimento, e associá-las à aplicação de quantidades adequadas nas culturas é uma das estratégias mais eficientes para a adubação nitrogenada. Muchow et al. (1996), destaca a importância de um manejo adequado da adubação nitrogenada para obtenção de uma alta produtividade na colheita.

Todavia, segundo Franco et al. (2011), a eficiência na utilização do nitrogênio pela cana-de-açúcar pode ser baixa e isso ocorre por vários motivos como, clima, intensidade luminosa, tipos de solos, irrigação, fixação biológica de nitrogênio, mineralização da matéria orgânica e dos restos culturais, época de adubação e desnitrificação. Outro ponto a ser considerado é a variabilidade genética que pode influenciar na dinâmica de absorção do nitrogênio e consequentemente influenciar na produtividade (Silva et al., 2018). Urquiaga et al. (1992), acreditam que a fixação biológica de nitrogênio está relacionada com características genéticas das variedades. Sendo assim, é imprescindível avaliar o comportamento agronômico de novas variedades com relação à adubação nitrogenada, tendo em vista a importância dessa cultura para o agronegócio e a economia brasileira.

O objetivo deste trabalho foi avaliar experimentalmente o efeito da adubação nitrogenada sobre o crescimento inicial de duas novas variedades de cana-de-açúcar (Saccharum spp.).

\section{Material e métodos}

0 experimento foi realizado em vasos com capacidade para $60 \mathrm{dm}^{3}$, dispostos em campo aberto no período de fevereiro a maio de 2017, no Centro de Ciências e Tecnologia Agroalimentar da Universidade Federal de Campina Grande, Campus de Pombal (CCTA/UFCG). 0 Município de Pombal está localizado nas coordenadas geográfica de referência $06^{\circ} 46^{\prime} 13^{\prime} \mathrm{S}$ e $37^{\circ} 48^{\prime} 06^{\prime} \mathrm{W}$, com altitude aproximada de $178 \mathrm{~m}$, situada na Microrregião do Sertão Paraibano a 387 km da capital João Pessoa, Estado da Paraíba, Nordeste do Brasil.

Foram estudadas cinco doses de adubação nitrogenada (1,3, 2,6, 5,3, 10,6 e $21,2 \mathrm{~g}$ /vaso) correspondentes a $20,40,80,160$ e $320 \mathrm{~kg}^{\mathrm{de}} \mathrm{N} \mathrm{ha}^{-1}$ de ureia em duas variedades de cana-de-açúcar, a RB992506 e a RB002754, liberadas em 2015 pelo 
Programa de Melhoramento Genético de Cana-de-Açúcar, da Universidade Federal Rural de Pernambuco, que é integrante da Rede Interuniversitária para o Desenvolvimento do Setor Sucroenergético (PMGCA/UFRPE/RIDESA).

Foi utilizado o delineamento experimental de blocos ao acaso, em esquema fatorial, $2 \times 5$, correspondente a duas variedades de cana-de-açúcar em cinco níveis de adubação nitrogenada com quatro repetições, totalizando assim 40 unidades experimentais. Os vasos foram preenchidos com uma camada de brita de $3 \mathrm{~cm}$ e com o solo de textura arenosa, cujas características físico-químicas são apresentadas na Tabela 1.

Tabela 1. Resultados da analise química do solo utilizado no experimento em amostra coletada antes da implantação dos experimentos. Pombal, PB.

\begin{tabular}{|c|c|c|c|c|c|c|c|c|c|}
\hline $\mathrm{pH}$ & $\mathrm{P}$ & $\mathrm{K}^{+}$ & $\mathrm{Na}^{+}$ & $\mathrm{Ca}^{+2}$ & $\mathrm{Mg}^{+2}$ & $\mathrm{H}^{+}+\mathrm{Al}^{+3}$ & CTC & MO & PST \\
\hline $\mathrm{H}_{2} \mathrm{O}$ & $\mathrm{Mg} \mathrm{dm}^{-3}$ & & & & $--\mathrm{Cmo}$ & $n^{-3}-\cdots$ & & $\mathrm{G} \mathrm{Kg}^{-1}$ & $\%$ \\
\hline 7.1 & 868 & 0.34 & 0.02 & 5.0 & 2.7 & 0.0 & 8.06 & 5.71 & $<1$ \\
\hline
\end{tabular}

P, K, Na: Extrator Mehlich1; Al, Ca, Mg: Extrator KCL 1M; $\mathrm{SB}=\mathrm{Ca}+2+\mathrm{Mg}+2+\mathrm{K}++\mathrm{Na}+; \mathrm{H}+\mathrm{Al}$ : Extrator Acetato de Cálcio 0,5 M, pH 7,0; CTC=SB+H++Al+3; M.O.: Digestão Úmida Walkley-Black; PST= Percentagem de Sódio Trocável. Composição granulométrica média: $854 \mathrm{~g} \mathrm{~kg}^{-1} \mathrm{de}_{\text {areia, }} 108 \mathrm{~g} \mathrm{~kg}^{-1}$ de silte e $38 \mathrm{~g} \mathrm{~kg}^{-1}$ de argila.

O plantio da cana-de-açúcar foi feito utilizando-se de rebolos de uma gema, sendo utilizados quatro rebolos por vaso, totalizando 160 rebolos. Após 30 dias foi realizado o desbaste, através do corte das plantas com um facão, mantendo-se apenas uma planta por vaso.

A adubação de fundação foi realizada de acordo com a análise química do solo, seguindo a recomendação proposta por Cavalcanti et al. (2008), que consistiu na aplicação de $20 \mathrm{~kg} \mathrm{ha}^{-1}$ de $\mathrm{P}_{2} \mathrm{O}_{5}$ e $30 \mathrm{~kg} \mathrm{ha}^{-1}$ de $\mathrm{K}_{2} \mathrm{O}$ nas formas de superfostato simples e cloreto de potássio respectivamente. A adubação de cobertura foi realizada 60 dias após o plantio com $30 \mathrm{~kg} \mathrm{ha}^{-1}$ de $\mathrm{K}_{2} \mathrm{O}$ na forma de cloreto de potássio. A aplicação das doses de nitrogênio foi realizada em três vezes 0,15 e 30 dias após o plantio (DAP), diluído em 20 L de água cada aplicação. As irrigações foram realizadas diariamente pela manhã e pela tarde, mantendo-se aproximadamente $80 \%$ da capacidade de campo durante todo o experimento.

Aos 120 DAP foram mensuradas as seguintes características: i) número de folhas (NF), ii) área foliar (AF), iii) altura do colmo (AC), iv) diâmetro médio do colmo (DMC), v) número de colmos (NC), vi) massa fresca das folhas (MFF), vii) massa seca das folhas (MSF), viii) massa fresca dos colmos (MFC), ix) massa seca dos colmos (MSC), x) massa fresca total da parte aérea (MFTPA) e xi) massa seca total da parte aérea (MSTPA).

A característica número de folhas (NF) foi obtida pela contagem do número total de folhas da planta. A área foliar (AF) foi determinada pela medição do comprimento da folha e da largura da porção mediana da mesma +3 , conforme metodologia descrita por Hermann e Câmara (1999), onde: $\mathrm{AF}=\mathrm{C} \times \mathrm{L}$ x 0,75 x $(\mathrm{N}+2)$, onde: $\mathrm{AF}$ é a área foliar por planta $\left(\mathrm{cm}^{2}\right)$; C é o comprimento da folha $+3(\mathrm{~cm})$; $\mathrm{N}$ é o número de folhas verdes expandidas e 0,75 e 2 como o fator de correção para a área foliar da cultura, em seguida transformado em $\left(\mathrm{m}^{2}\right)$.

A altura do colmo (AC) foi medida em metros (m), do nível do solo até o primeiro "dewlap" visível (inserção da folha +1) com o auxílio de trena graduada. 0 diâmetro médio do colmo (DMC) foi obtido na altura média do colmo com o auxílio de um paquímetro com precisão de $1 \mathrm{~mm}$, em seguida transformado em $\left(\mathrm{m}^{2}\right)$. 0 número de colmos (NC) foi obtido pela contagem do número total de colmos por vasos. As massas fresca e seca das folhas (MFF e MSF), massas fresca e seca dos colmos (MFC e MSC) e as massas fresca e seca total 
da parte aérea (MFTPA e MSTPA), foram obtidas a partir de pesagens, em $\mathrm{kg}$, usando uma balança de precisão. As características NF, AF, AC, DMC foram obtidas na cana mãe, que é o primeiro perfilho que nasce da touceira. Já as variáveis MFF, MSF, MFC, MSC e NC foram obtidas de todas as plantas do vaso.

Os dados foram submetidos à análise da variância e de regressão e as médias foram agrupadas ao teste Scott-Knott em nível de 5\% de probabilidade, além disso, foram estimados os parâmetros genéticos com o objetivo de verificar se existe resposta a adubação nitrogenada devido a efeitos genéticos. As análises estatísticas foram realizadas com o auxílio do programa Genes (Cruz, 2006) e Sisvar 5.6 (Ferreira et al., 2011).

\section{Resultados e discussão}

A análise de variância mostrou efeito, em relação às variedades (V) de cana-deaçúcar para as variáveis, número de folhas (NF) e de colmos (NC), área foliar (AF), diâmetro médio do colmo (DMC), massa fresca (MFC) e seca do colmo (MSC), e massa fresca (MFTPA) e seca total da parte aérea (MSTPA). Para o fator doses de nitrogênio (D), houve efeito para as variáveis, número de colmo, área foliar, diâmetro médio do colmo, altura do colmo, massa fresca e seca da folha, massa fresca e seca do colmo, e massa fresca e seca total da parte aérea. Na interação dos fatores $V \times$ D houve efeito significativo para as variáveis, número de folhas, massa seca do colmo e massa seca total da parte aérea, respectivamente (Tabela 2 ).

Tabela 2. Resumo da análise de variância para as variáveis número de folhas (NF), número de colmos (NC), área foliar (AF), diâmetro médio do colmo (DMC), altura do colmo (AC), massa fresca das folhas (MFF),massa seca das folhas (MSF), massa fresca dos colmos (MFC), massa seca dos colmos (MSC), massa fresca total da parte aérea (MFTPA) e massa seca total da parte aérea (MSTPA), Pombal, PB.

\begin{tabular}{|l|c|c|c|c|c|c|}
\hline & Variedade (V) & Doses (D) & V x D & Bloco & Resíduo & C.V (\%) \\
\hline NF & $3,60^{* *}$ & $0,18^{\text {ns }}$ & $2,16^{* *}$ & $0,60^{\text {ns }}$ & 0,41 & 7,58 \\
\hline NC & $136,90^{* *}$ & $111,06^{* *}$ & $1,46^{\text {ns }}$ & $0,96^{\text {ns }}$ & 2,94 & 12,49 \\
\hline AF & $0,0240^{* *}$ & $0,0132^{* *}$ & $0,0004^{\text {ns }}$ & $0,0026^{\text {ns }}$ & 0,0012 & 10,38 \\
\hline DMC & $0,00010^{* *}$ & $0,00001^{* *}$ & $0,000001^{\text {ns }}$ & $0,000002^{\text {ns }}$ & 0,000002 & 5,90 \\
\hline AC & $0,0013^{\text {ns }}$ & $0,1407^{* *}$ & $0,0040^{\text {ns }}$ & $0,0047^{\text {ns }}$ & 0,0033 & 5,12 \\
\hline MFF & $0,0092^{\text {ns }}$ & $0,4033^{* *}$ & $0,0013^{\text {ns }}$ & $0,0023^{\text {ns }}$ & 0,0025 & 8,55 \\
\hline MSF & $0,0012^{\text {ns }}$ & $0,0324^{* *}$ & $0,002^{\text {ns }}$ & $0,005^{\text {ns }}$ & 0,007 & 14,64 \\
\hline MFC & $3,07^{* *}$ & $2,77^{* *}$ & $0,17^{\text {ns }}$ & $0,05^{\text {ns }}$ & 0,06 & 12,55 \\
\hline MSC & $0,230^{* *}$ & $0,188^{* *}$ & $0,022^{*}$ & $0,007^{\mathrm{ns}}$ & 0,005 & 14,43 \\
\hline MFTPA & $3.21^{* *}$ & $5,01^{* *}$ & $0,16^{\text {ns }}$ & $0,06^{\text {ns }}$ & 0,08 & 11,00 \\
\hline MSTPA & $0,266^{* *}$ & $0,344^{* *}$ & $0,025^{*}$ & $0,009^{\text {ns }}$ & 0,007 & 12,26 \\
\hline GL & 1 & 4 & 4 & 3 & 27 & \\
\hline
\end{tabular}

** e * Significativo a 1 e $5 \%$ de probabilidade, respectivamente, pelo teste $\mathrm{F}$, não significativo(ns).

O efeito positivo obtido nas variedades de cana, a partir da variação nas dosagens de nitrogênio, reflete variação genética entre elas e que as mesmas respondem diferentemente à adubação nitrogenada recebida. Assim, pode-se inferir que as características NC e DMC se correlacionam com importantes componentes de produção. Espósito et al. (2012), ao estudarem as correlações e análise de trilha, concluíram que NC e DMC correlacionam-se positivamente com a produtividade de cana por hectare. Sendo assim, é possível obterem-se maiores produtividades nas colheitas se houverem manejos 
adequados na adubação nitrogenada nas fases iniciais do ciclo fenológico das variedades utilizadas.

Para o efeito das doses, a maioria das variáveis apresentou efeito significativo (p < $0,01)$, indicando que as doses funcionam como ambientes contrastantes, podendo influenciar na expressão das características avaliadas. Sanchez-Roman et al. (2015), obtiveram resultados semelhantes ao verificarem a influência do nitrogênio sob características de produtividade de açúcar da variedade RB855453. Esses autores atribuem o efeito significativo do nitrogênio nas características da planta em virtude do fornecimento do fertilizante em pequenas dosagens ao longo do ciclo de cultivo, aumentando assim a absorção e favorecendo o aproveitamento do nitrogênio. Portanto, no presente trabalho o efeito significativo do nitrogênio pode estar associado ao fornecimento do mesmo na fase de estabelecimento da cana-de-açúcar.

Pelo teste Scott-Knott aplicado, a 5\% de probabilidade, observa-se que houve a formação de grupos para a maioria das características avaliadas com exceção das características AC, MFF e MSF (Tabela 3).

Tabela 3. Agrupamento de médias referente às variáveis, número de folhas (NF), número de colmos (NC), área foliar (AF), diâmetro médio do colmo (DMC), altura do colmo (AC), massa fresca das folhas (MFF), massa seca das folhas (MSF), massa fresca dos colmos (MFC), massa seca dos colmos (MSC), massa fresca total da parte aérea (MFTPA) e massa seca total da parte aérea (MSTPA), Pombal, PB.

\begin{tabular}{|l|c|c|}
\hline \multirow{2}{*}{ Variáveis } & \multicolumn{2}{|c|}{ Variedades } \\
\cline { 2 - 3 } & RB992506 & RB002754 \\
\hline NF & $8,20 \mathrm{~b}$ & $8,80 \mathrm{a}$ \\
\hline NC & $15,60 \mathrm{a}$ & $0,370 \mathrm{~b}$ \\
\hline AF & $0,321 \mathrm{~b}$ & $0,025 \mathrm{a}$ \\
\hline DMC & $0,022 \mathrm{~b}$ & $1,13 \mathrm{a}$ \\
\hline AC & $1,12 \mathrm{a}$ & $0,59 \mathrm{a}$ \\
\hline MFF & $0,58 \mathrm{a}$ & $0,17 \mathrm{a}$ \\
\hline MSF & $0,18 \mathrm{a}$ & $1,78 \mathrm{~b}$ \\
\hline MFC & $2,33 \mathrm{a}$ & $0,44 \mathrm{~b}$ \\
\hline MSC & $0,59 \mathrm{a}$ & $2,37 \mathrm{~b}$ \\
\hline MFTPA & $2,93 \mathrm{a}$ & $0,62 \mathrm{~b}$ \\
\hline MSTPA & $0,78 \mathrm{a}$ & \\
\hline
\end{tabular}

As médias seguidas pela mesma letra pertencem ao mesmo grupo, pelo teste de Scott Knott a 5\% de probabilidade.

A variedade RB992506 apresentou um aumento de 23,7 e 23,6\% em relação ao número de colmos e massa fresca de colmos quando comparado à variedade RB002754 respectivamente, mostrando que a mesma respondeu melhor à adubação nitrogenada (Tabela 2). Já as características NF, AF e DMC, a variedade RB002754 apresentou melhor desempenho. Logo, é possível constatar a importância da adubação nitrogenada na fase de estabelecimento da cana-de-açúcar, pois se a mesma contribuiu para maior desenvolvimento de NC, MFC, MFT, MSC e MST, na variedade RB992506, como também para NF, AF, DMC, na variedade RB002754, espera-se maior produtividade nas colheitas, já que essas características, principalmente $\mathrm{NC}$ e DMC, estão positivamente correlacionadas com a produtividade de cana por hectare, conforme demonstraram Dutra Filho et al. (2011) e Espósito et al. (2012).

Observando-se a análise de regressão (Figura 1), verifica-se que na variedade RB002754 (V2) o incremento nas doses de nitrogênio (320 kg ha-1) promoveu um 
aumento de $14.5 \%$ no número de folhas (NF), quando comparado com a falta de aplicação desse nutriente. É conhecido o fato de que número de folhas é uma importante característica a ser avaliada, pois estas estruturas influenciam na captação de $\mathrm{CO}_{2}$ e energia solar e que, quanto maior o número de folhas, maior é a produção de fotoassimilados. 0 nitrogênio é um nutriente requerido em altas quantidades pelas plantas, pois é responsável pelo metabolismo e são constituintes de enzimas, proteínas, DNA, RNA, clorofilas e precursores de hormônios (Silva et al., 2014),o que pode justificar o ganho de biomassa.

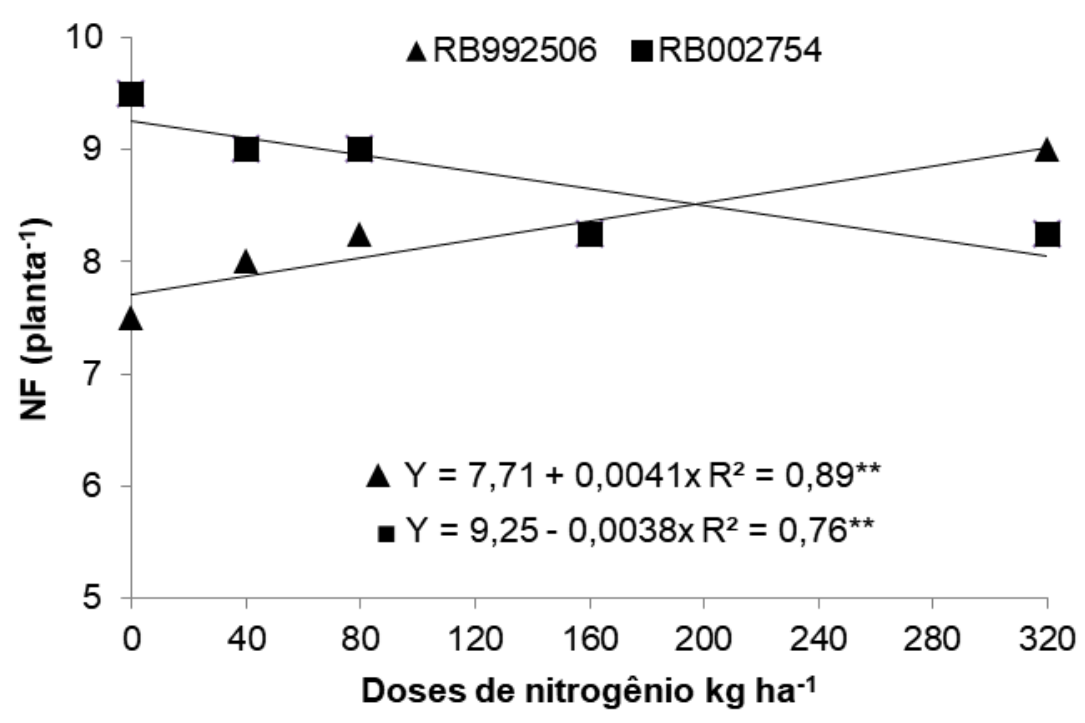

Figura 1. Número de folhas das variedades de cana-de-açúcar RB992506 (V1) e RB002754 (V2) adubadas com diferentes níveis de nitrogênio.

Para a variedade RB992506 (V1), houve declínio no número de folhas em virtude do aumento dos níveis de nitrogênio. A média do número de folhas na ausência de adubação foi de 9.5\%, passando para $8.25 \%$ quando submetida a $320 \mathrm{~kg} \mathrm{ha}^{-1}$ de nitrogênio, resultando num declínio de $15.15 \%$ do número de folhas. Esse resultado pode estar associado a distúrbios nutricionais, ocasionado pelo excesso de nitrogênio para essa variedade. Muito provavelmente a variedade em questão utiliza mais eficientemente o nitrogênio necessitando de menores quantidades quando comparado à variedade RB002754. A Análise de parâmetros fisiológicos pode elucidar esse mecanismo e fornecer uma resposta adequada.

Na Figura 2, observa-se que a dose máxima que proporcionou maior massa do colmo foi na aplicação de $240 \mathrm{~kg} \mathrm{ha}^{-1}$ de nitrogênio obtido na variedade RB992506, quando comparado a não aplicação de $\mathrm{N}$ no solo, a massa do colmo teve um aumento de $159,3 \%$ na respectiva dose. A variedade RB002754 (V2) também apresentou comportamento quadrático, tendo maior acúmulo de massa alcançado com a dose de $183.3 \mathrm{~kg} \mathrm{ha}^{-1}$ de nitrogênio que representa um aumento de $37.15 \%$ na massa seca do colmo em comparação com a não aplicação do nitrogênio. Este resultado é importante, pois demonstra, de acordo com Muchow et al. (1996), a importância de um manejo adequado para aplicação de fertilizantes nitrogenados no crescimento inicial da cana-deaçúcar, explorando assim o potencial produtivo das variedades (Figura 2). 


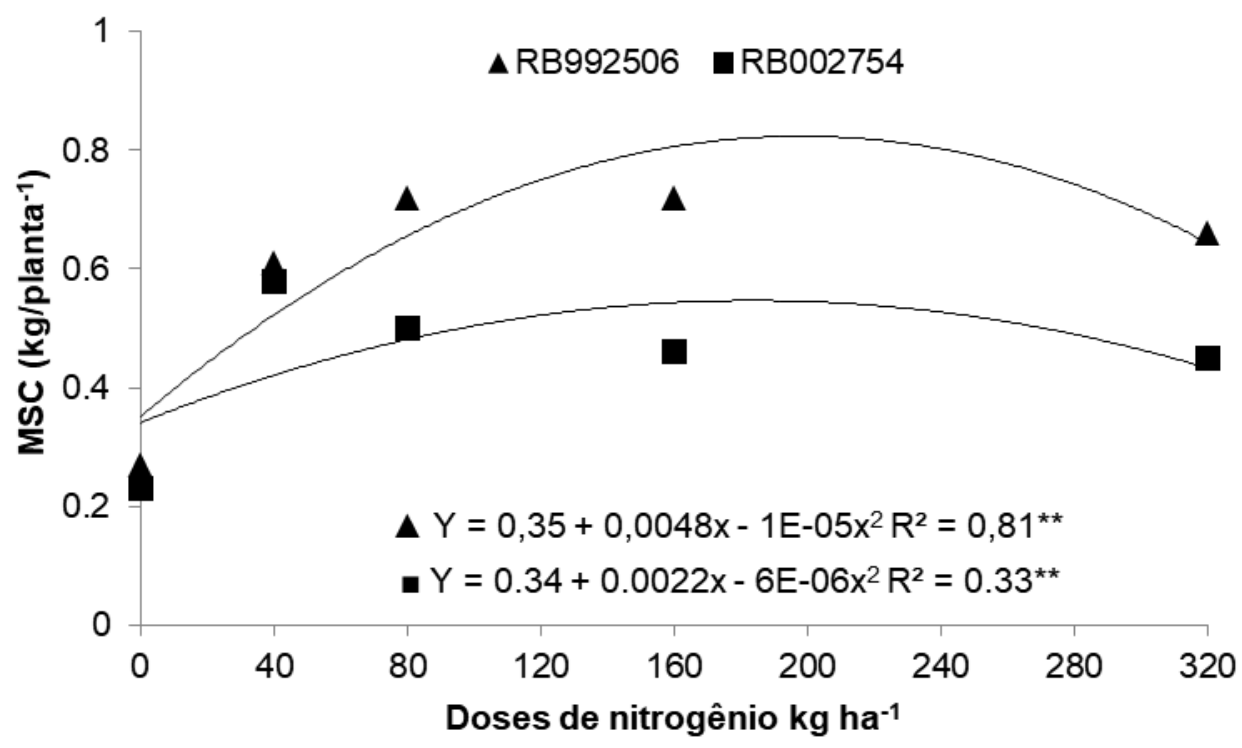

Figura 2. Massa seca do colmo em kg das variedades de cana-de-açúcar adubadas com diferentes doses de nitrogênio.

Para variável massa fresca total da parte aérea (Figura 3), observa-se comportamento quadrático nas variedades. A variedade RB992506 apresentou seu maior acúmulo na dose de $157.5 \mathrm{~kg} \mathrm{ha}^{-1}$ e a variedade RB002754 aos $190 \mathrm{~kg} \mathrm{ha}^{-1}$. Quando comparadas com a não aplicação do nitrogênio houve um aumento de 53\% e 46,2\%, respectivamente.

É importante destacar que houve redução na massa fresca total da parte aérea em função do aumento das doses de nitrogênio até $320 \mathrm{~kg} \mathrm{ha}^{-1}$, essa redução foi de $56,4 \%$ e $32,4 \%$ respectivamente. É fundamental verificar com atenção esses resultados, pois o aumento de 50.7 e $40.6 \%$ na dose de nitrogênio não refletiu em produção de massa para as variedades RB992506 e RB002754, sendo assim, o planejamento da adubação da canade-açúcar torna-se uma importante ferramenta para que o produtor não tenha perdas econômicas. Segundo Holst et al. (2012) a cana-de-açúcar requer grande demanda de nitrogênio, e isso tem alto custo financeiro e energético dos fertilizantes nitrogenados, além de riscos ambientais relacionados à adição de nitrogênio mineral no sistema, assim a sua aplicação correta reduz consideráveis perdas.

Em relação aos parâmetros genéticos, observa-se variância genética superior a variância ambiental para a maioria das características avaliadas (Tabela 4). 


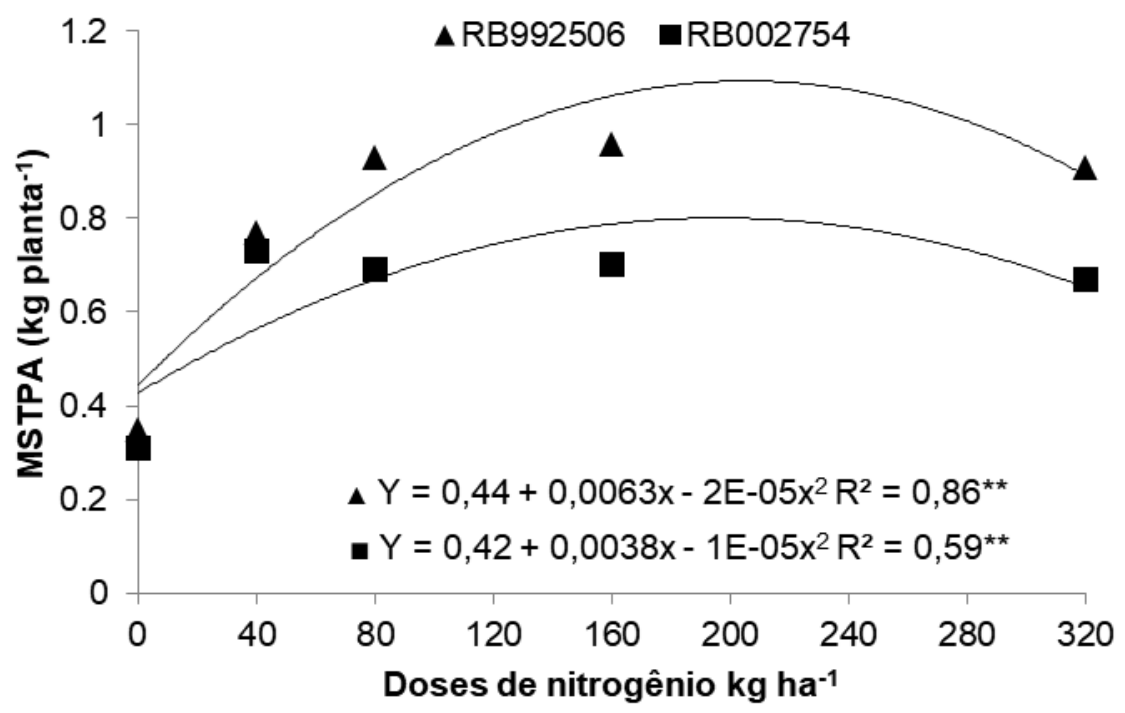

Figura 3. Massa seca total da parte aérea (MSTPA) em kg planta-1 das variedades de cana-de-açúcar RB992506 e RB002754 adubadas com diferentes doses de nitrogênio.

Tabela 4. Parâmetros genéticos das variáveis número de folhas (NF), número de colmos (NC), área foliar (AF), diâmetro médio do colmo (DMC), altura do colmo (AC), massa fresca das folhas (MFF), massa seca das folhas (MSF), massa fresca dos colmos (MFC), massa seca dos colmos (MSC), massa fresca total da parte aérea (MFTPA) e massa seca total da parte aérea (MSTPA), Pombal, PB.

\begin{tabular}{|c|c|c|c|c|}
\hline Variáveis & VF & VG & VA & $\mathbf{H}^{\mathbf{2}}$ \\
\hline $\mathrm{NF}$ & 0,9 & 0,8 & 0,1 & 88 \\
\hline $\mathrm{NC}$ & 34,2 & 33,4 & 0,71 & 96 \\
\hline $\mathrm{AF}$ & 0,005 & 0,004 & 0,001 & 80 \\
\hline $\mathrm{DMC}$ & 0,000025 & 0,000020 & 0,000005 & 80 \\
\hline $\mathrm{AC}$ & 0,00 & 0,00 & 0,00 & 00 \\
\hline $\mathrm{MFF}$ & 0,00 & 0,00 & 0,00 & 00 \\
\hline MSF & 0,00 & 0,00 & 0,00 & 00 \\
\hline MFC & 0,77 & 0,75 & 0,02 & 97 \\
\hline MSC & 0,05 & 0,04 & 0,01 & 80 \\
\hline MFTPA & 0,80 & 0,78 & 0,02 & 98 \\
\hline MSTPA & 0,06 & 0,05 & 0,01 & 83 \\
\hline
\end{tabular}

VF: variância fenotípica, VG: variância genética e VA: variância ambiental, $\mathrm{H}^{2}$ : herdabilidade.

Este é um indicativo de que a expressão dessas características é devida, em sua maior parte, aos efeitos genéticos, de acordo com Dutra Filho et al. (2014). Desse modo, pode-se inferir que as diferenças entre as variedades com relação à adubação nitrogenada devem-se, predominantemente, ao potencial genético.

Os altos valores do coeficiente de determinação genotípico é um indicativo de sucesso na seleção com perspectivas favoráveis de ganhos genéticos através da recombinação das variedades em trabalhos de hibridação, conforme destacado por Albuquerque et al. (2016). Os altos valores do coeficiente de determinação genotípico revelam uma alta probabilidade do potencial genético dessas variedades com relação à resposta a adubação nitrogenada serem transmitidas às suas progênies em trabalhos de hibridação. 


\section{Conclusões}

A adubação nitrogenada influencia positivamente na fase de estabelecimento da variedade RB002754, com maior efeito nas características NF, MSC e MSTPA.

A resposta à adubação nitrogenada deve-se, predominantemente, ao potencial genético das variedades.

A variedade RB992506 foi a que melhor se adaptou a adubação nitrogenada, em termos de maior número de colmos e massa fresca do mesmo.

\section{Conflito de interesses}

Os autores declaram não haver conflito de interesses.

\section{Agradecimentos}

Os autores agradecem ao CNPq/UFCG, Conselho Nacional de Desenvolvimento Científico e Tecnológico pelo apoio financeiro através da bolsa de estudos e à Estação Experimental de Cana-de-Açúcar de Carpina, pelo fornecimento das variedades.

\section{Referências}

Albuquerque, A. P.; Bastos, G. Q.; Dutra Filho, J. A.; Neto, D. E. S.; Silva, L. J.; Souto, L. S. Comportamento de genótipos de maturação precoce de cana-de-açúcar na Zona da Mata de Pernambuco. Comunicata Scientiae, v. 7, n. 3, p.311-318, 2016. https://doi.org/ 10.14295/CS.v7i3.1258

Cavalcanti, F. J. A.; Cavalcanti, F.; Cavalcanti, F. C. I.; Cavalcanti, M.; Cavalcanti, A.; Andrade, G. L. (Coords.). Recomendações de adubação para o Estado de Pernambuco. Recife: Instituto Agronômico de Pernambuco, 2008.

Cruz, C. D. Programa Genes: biometria. Viçosa: UFV, 2006.

Dutra Filho, J. A.; Melo, L. J.; Simões Neto, D. E.; Anunciação Filho, C. J.; Bastos, G. Q.; Daros, E. Seleção de progênies e correlação de componentes de produção em cana-de-açúcar. Revista Brasileira de Ciências Agrárias, v. 6, n. 3, p. 432-439, 2011.

Dutra Filho, J. A.; Junior, T. C.; Simões Neto, D. E. Phenotype adaptability and stability of sugarcane genotypes in the sugarcane belt of the State of Pernambuco, Brazil. Genetics and Molecular Research, v. 13, n. 3, p. 6865-6877, 2014. https://doi.org/10.4238/ 2014.August.29.8

Dutra Filho, J. A.; Junior, T. C.; Simões Neto, D. E. Genetic analyses, phenotypic adaptability and stability in sugarcane genotypes for commercial cultivation in Pernambuco, Brazil. Genetics and Molecular Research, v. 14, n. 4, p. 12102-12110, 2015. https://doi.org/ 10.4238/2015.0ctober.5.23

Espósito, D. P.; Peternelli, L. A.; Paula, T. O. M. D.; Barbosa, M. H. P. Análise de trilha usando valores fenotípicos e genotípicos para componentes do rendimento na seleção de famílias de cana-de-açúcar. Ciência Rural, v. 42, n. 1, p. 38-44, 2012. https://doi.org/10.1590/ S0103-84782011005000152

Fabris, L. B.; Foloni, J. S. S.; Calonego, J. C.; Santos, D. H.; Santos, G. S.; Silva, P. C. G Produtividade e desempenho de cana soca cultivada em diferentes espaçamentos e doses de adubação nitrogenada em cobertura. Revista Agrarian, v. 6, n. 21, p. 252-258, 2013. 
Fernandes, M. F.; Procopio, S. D. O.; Teles, D. A.; Sena Filho, J. G.; Cargnelutti Filho, A.; Andrade, C. Crescimento e fixação biológica de nitrogênio de Gluconacetobacter diazotrophicus na presença de inseticidas utilizados na cultura da cana-de-açúcar. Ciência Agrária, v. 56, n. 1, p. 12-18, 2016.

Ferreira, D. F. Sisvar: a computer statistical analysis system. Ciência e Agrotecnologia, v. 35, n. 6, p. 1039-1042, 2011. https://doi.org/10.1590/S1413-70542011000600001

Franco, H. C. J.; Otto, R.; Faroni, C. E.; Vitti, A. C.; Oliveira, E. C. A.; Trivelin, P. C. O. Nitrogen in sugarcane derived from fertilizer in Brazilian field conditions. Field Crops Research, v. 121, n. 1, p. 29-41, 2011. https://doi.org/10.1016/j.fcr.2010.11.011

Hermann, E. R.; Câmara, G. M. S. Um método simples para estimar a área foliar de cana-deaçúcar. Revista da STAB, v. 17, n. 5, p. 32-34, 1999.

Holst, J.; Brackin, R.; Robinson, N.; Lakshmanan, P.; Schmidt, S. Soluble inorganic and organic nitrogen in two Australian soils under sugar cane cultivation. Agriculture, Ecosystems and Environment, v. 155, n. 1, p. 16-26, 2012. https://doi.org/10.1016/ j.agee.2012.03.015

Malavolta, E. Manual de química agrícola: adubos e adubação. São Paulo: CERES, 1981.

Muchow, R. C.; Robertson, M. J.; Wood, A. W.; Keating, B. A. Effect of nitrogen on the time course of sucrose accumulation in sugar cane. Field Crop Research, v. 47, n. 3, p. 143-153, 1996. https://doi.org/10.1016/0378-4290(96)00022-6

Okumura, R. S.; Mariano, D. C.; Zaccheo, P. V. C. Uso de fertilizante nitrogenado da cultura do milho: uma revisão. Revista Brasileira de Tecnologia Aplicada nas Ciências Agrárias, v. 4, n. 2, p. 226-244, 2011.

Pires, W. M.; Teixeira, M. B.; Soares, F. A. L.; Ribeiro, W. A.; Lopes Filho, L. C. Cultivo da cana-de-açúcar sob diferentes níveis de reposição hídrica, com e sem adição de nitrogênio. Científic@-Multidisciplinary Journal, v. 5, n. 3, p. 56-87, 2018. https://doi.org/ 10.29247/2358-260X.2018v5i3.p56-87

Sanches-Román, R. M.; Silva, N. F.; Cunha, F. N.; Teixeira, M. B.; Soares, F. A. L.; Ribeiro, P. H. P. Produtividade da cana-de-açúcar submetida a diferentes reposições hídricas e nitrogênio em dois ciclos. Irriga, v. 1, n. 1, p. 198-210, 2015. https://doi.org/ 10.15809/irriga.2015v1n1p198

Silva, N. F.; Cunha, F. N.; Oliveira, R. C.; Freitas Moura, L. M.; Campos Bastos, F. J.; Teixeira, M. B. Crescimento da cana-de-açúcar sob aplicação de nitrogênio via gotejamento subsuperficial. Revista Brasileira de Agricultura Irrigada, v. 8, n. 1, p. 1-11, 2014.

Silva, V. S. G.; Oliveira, M. W.; Ferreira, V. M.; Oliveira, T. B. A.; Brito Santana, M.; Galvão, E. R. Stalk yield and nutrients accumulation of sugarcane varieties in three crop cycles. Revista de Ciências Agrárias, v. 41, n. 2, p. 415-423, 2018. https://doi.org/ 10.19084/RCA17051

Urquiaga, S.; Cruz, K. H.; Boddey, R. M. Contribution of nitrogen fixation to sugarcane: Nitrogen-15 and nitrogen-balance estimates. Soil Science Society of America Journal, v. 56, n. 1, p. 105-114, 1992. https://doi.org/10.2136/sssaj1992.03615995 $005600010017 \mathrm{x}$

Informação da Licença: Este é um artigo Open Access distribuído sob os termos da Licença Creative Commons Attribution, que permite uso irrestrito, distribuição e reprodução em qualquer meio, desde que a obra original seja devidamente citada. 